\title{
A INTERTEXTUALIDADE E SUA TEIA Da Etnografia ao Romance e do Romance ao Filme
}

\section{José Hildo de Oliveira Filho}

Universidade de Lund, Lund, Suécia. E-mail: ssg13jol@student.lu.se

DOI: http//dx.doi.org/10.17666/3089129-146/2015

\section{Introdução}

Em "Por uma ciência das obras", Pierre Bourdieu (1997) contrapõe leituras internas e leituras externas das obras científicas e artísticas. As primeiras não fariam qualquer referência aos contextos histórico e social e não poderiam explicar as mudanças estéticas e científicas a não ser pelo recurso à "vontade" de cientistas e artistas. Seriam leituras inférteis porque a-históricas, portanto. Já as leituras externas, realizadas principalmente por autores marxistas, como Lucien Goldmann, apesar de incorporar a história no universo da análise, operam uma redução das obras e dos autores a seus pontos de vista de classe. O problema bourdiano está, portanto, em levar a cabo uma análise que incorpore tanto a estrutura das mensagens científicas

Artigo recebido em 10/11/2013

Aprovado em 31/07/2015 e artísticas como a história específica dos campos analisados, o que Bourdieu denomina "espaço de possíveis”. Retemos de Bourdieu, então, um princípio de análise: o de que as obras constituem formas de debate, de confrontos e são construções social e historicamente situadas (Bourdieu, 2003). Buscamos demonstrar este princípio através dos debates públicos travados entre os produtores culturais que analisamos a seguir.

Se Bourdieu tem o mérito de propor novas formas de análise de obras, é preciso ressaltar que, para o sociólogo francês, a intertextualidade refere-se a uma relação histórica interna entre textos e se situa como método por excelência de leituras internalistas. No entanto, para nós, acolher a intertextualidade nas ciências sociais significa adotar não só os discursos como matérias-primas, mas, sobretudo, pôr-nos diante de seus confrontos, questionando os constrangimentos de sua própria produção e recepção. ${ }^{1}$ É precisamente a obra de Edward Said 
$(2003,2005)$ que mostra a intertextualidade como uma forma de acolher fluxos globais e desconstruir estereótipos sobre certos grupos e sociedades. ${ }^{2}$

Neste trabalho, visamos ampliar - e produzir novas questões e interpretações - uma análise já realizada por Keila Costa Prado (2008) sobre as relações entre $A$ máquina e a revolta (2000), de Alba Zaluar, o romance Cidade de Deus (1997, 2007), de Paulo Lins, e o filme homônimo dirigido por Fernando Meirelles e Katia Lund (2002). Explorar esta teia intertextual significa compreender como diferentes discursos, inspirados por diferentes campos e constrangimentos, constroem significados diversos para lidar com a pobreza e a violência. $\mathrm{O}$ trabalho de Costa Prado é interessante exatamente por mostrar as muitas formas de entrelaçamento entre a etnografia de Zaluar, o romance de Lins e o filme de Meirelles e Lund. Há uma série de estudos sobre Cidade de Deus, e nosso propósito com este trabalho não é esgotar o debate sobre essas obras. No entanto, muitas análises mantêm-se em suas fronteiras disciplinares. As teses e as dissertaçōes de Rocha (2007), Péret (2009), Wildhagen (2007) e Quitério (2012) somente mencionam a etnografia de Zaluar como algo complementar e anterior ao romance e ao filme Cidade de Deus. Suas análises são focadas no romance e no filme como objetos estéticos semiautônomos. A etnografia parece não ter tanta importância, portanto. Assim, o que buscamos neste trabalho é dar mais ênfase à antropologia sem descuidar da especificidade do romance e do filme.

\section{Uma história de (dis)conexões}

Alba Zaluar, ao colocar-se no papel de mediadora entre os intelectuais uspianos e os moradores de Cidade de Deus, trabalhou, durante nove anos, com Paulo Lins, morador da Cidade de Deus e acadêmico de letras, em seus contatos iniciais. Lins, por conta dessa longa inteiração com as pesquisas de Zaluar e, assim, cada vez mais familiarizado com as abordagens antropológicas sobre pobreza e violência, utilizou ostensivamente, para a elaboração de seu romance, os relatos dos moradores de Cidade de Deus recolhidos durante a pesquisa etnográfica. Segundo o autor, apesar de conturbado, o processo de construção do romance foi definitivamente impulsionado quando ele, com a mediação de Alba Zaluar, se encontrou com Roberto Schwarz, responsável por sua candidatura à bolsa Vitae de Artes, sem a qual o romance não teria sido concluído. Schwarz também foi o responsável pela recomendação da edição do livro. Assim, a mediação de Zaluar e Schwarz foi fundamental para que Cidade de Deus ganhasse vida (Schwarz, 2001).

A edição do romance aparentemente vem acompanhada de uma fusão de perspectivas. Alba Zaluar, por exemplo, fez uma crítica elogiosa à sua primeira edição (1997), nomeando Cidade de Deus como um "romance etnográfico". No entanto, após o lançamento do filme, houve uma controvérsia extremamente interessante do ponto de vista antropológico. São bem conhecidos os debates entre Zaluar e Paulo Lins após o lançamento do filme. A autora acusou o autor de ter utilizado indiscriminadamente relatos dos moradores de Cidade de Deus sem preservar sua intimidade; Lins refutou dizendo que somente escrevera uma obra de ficção. Nessa discussão, transparece a antropóloga analisando o romance segundo os dilemas éticos enfrentados pela antropologia no que concerne à divulgação e à interpretação dos relatos dos sujeitos envolvidos na pesquisa. A resposta de Lins invoca a autonomia de sua ficção diante da vida cotidiana dos moradores de Cidade de Deus. Em suma, o romance de Lins, após o filme, deixaria de ser um "romance etnográfico" para se tornar uma "mera ficção", com limites éticos discutíveis.

O conflito entre Zaluar e Paulo Lins mostra, além disso, algo descortinado pela sociologia da arte de Pierre Bourdieu (2007), a saber: a estreita relação entre uma maior autonomia do campo artístico e um tipo de percepção estética. Percepção esta que despreza a função das obras de arte em nome da forma artística. Veremos adiante que Paulo Lins busca, ao descrever com detalhe seu processo criativo, sua legitimação como artista. É a partir de uma forma específica de realizar seu romance que Lins pretende se manter afastado das consequências éticas e políticas de sua escrita.

Apesar de os debates entre a antropóloga e o escritor enfatizarem o caráter antagônico entre ficção e etnografia, o romance e a descrição etnográ- 
fica complementam-se em muitos aspectos (Rocha, 2007). Por exemplo, ao falar das relações entre trabalhadores e bandidos, Zaluar constrói duas éticas em conflito presentes em Cidade de Deus. Os trabalhadores possuiriam a ética do provedor; e ser responsável pela gerência de uma família seria sua fonte de orgulho. Os bandidos menosprezam tal ética, afirmando a incapacidade dos trabalhadores de ter acesso a bens de consumo das classes dominantes. ${ }^{3}$ Zaluar busca realizar um exercício de reflexão sobre as constantes relações entre trabalhadores e bandidos. Enfatiza que apesar de existirem duas éticas distintas, a relação entre bandidos e trabalhadores no cotidiano é mais ambígua do que aparece à primeira vista.

No romance, a separação entre trabalhadores e bandidos é muitas vezes construída a partir de um dualismo entre migrantes nordestinos e a "comunidade" de Cidade de Deus. Os migrantes representariam um "tipo ideal" da ética de provedor e, por meio de representações raciais bastante carregadas, se oporiam aos negros do bairro. São personagens que se estabeleceram no Rio de Janeiro para o trabalho e não toleram nem o crime nem os criminosos, permanecendo sempre ao lado da polícia. Por isso eles seriam o "tipo ideal" de trabalhador, segundo a descrição Alba Zaluar. ${ }^{4}$

Com este exemplo, não queremos encorajar uma leitura etnográfica do romance, no sentido de descobrir "as verdades a respeito do cotidiano de Cidade de Deus" não reveladas por Alba Zaluar. Buscamos simplesmente desencorajar uma leitura puramente estética de Cidade de Deus. Paulo Lins, ao falar sobre a construção de seu romance, assim a descreve:

É, fui trabalhando o vocabulário, as palavras que só eram usadas lá, fui juntando tudo e saquei que o assunto tinha de ser o crime... E não parava de ler desesperadamente poesia. Comecei tentando fazer variações com os versos dos poemas. E quando vi a tradução de Maiakovski de Haroldo de Campos e de Décio Pignatari, eles diziam que Maiakovski fazia sessenta variações do mesmo verso. Sabe, o cara batalhava! Era aquela coisa do labor da poesia... 90\% da poesia era transpiração, o resto é inspiração. E eu fiquei com isso na cabeça e comecei a fichar o romance. $\mathrm{Na}$ realidade, eu reescrevia os romances que admirava. Eu pegava os capítulos e ia fazendo mutações no texto. Reescrevi Fogo Morto inteiro. Aquele romance de José Lins do Rego é maravilhoso, me deixou louco com o sentimento pela linguagem. Roberto [Schwarz] falou uma coisa: Ô Paulo, pôe sentimento . Então roubei passagens inteiras de Fogo Morto. Quando Mané Galinha vê o irmão dele morto, é a mesma coisa quando Lula Chacon de Holanda fala pro mestre José Amaro: Vai embora da minha fazenda. E ele pega e sai, falando assim: Vai passando assim pela estrada, com o diabo no seu coração batendo forte... ${ }^{5}$

A versão de Paulo Lins, mesmo que neste trecho mencione sua relação com Roberto Schwarz, enfatiza o labor estético de sua construção novelística, que trava um diálogo direto com o romance social dos anos de 1930 e 1940 (Bosi, 1994). No entanto, para não ficarmos nem com a versão de Zaluar nem com a versão de Lins, precisamos de uma análise mais detalhada de $A$ máquina e a revolta e Cidade de Deus. É o que propomos realizar adiante.

Outro ponto deve ser levado em consideração: após o lançamento do filme, Paulo Lins reescreveu seu romance, suprimindo aproximadamente 140 páginas e mudando os nomes das personagens (Lins, 1997, 2007; Prado, 2008; Rocha, 2007). Sabemos que após o sucesso do filme, o romance ganhou grande visibilidade e os dilemas éticos levantados por Alba Zaluar ficaram mais evidentes. Segundo o rapper MVBill, a respeito do impacto do filme sobre o bairro: "Dei ao Paulo Lins, Katia Lund, Vídeo Filmes, O2, Globo Filmes e todos os seus aliados a chance de reverter e repensar uma postura social em relação à comunidade Cidade de Deus. [...] Apenas disse, e digo, que Cidade de Deus ganharia o Oscar e nossa favela ganharia o Oscar da Violência” (Clique Music UOL, 2003).

Isso reforça o que já havia sido apontado por Alba Zaluar ${ }^{6}$ : a projeção de representações lineares e distorcidas sobre a relação entre pobreza e violên$\mathrm{cia}^{7}$ levou MVBill a fazer tal pronunciamento ( $\mathrm{Ri}$ beiro, 2003). A mudança de nome das personagens 
do romance, em sua segunda edição, foi justificada por Lins com base no distanciamento entre filme e romance. No entanto, interpretamo-la como uma maneira de evitar novas leituras e novas formas de produção cultural a partir do discurso dos moradores de Cidade de Deus (Mello, 2010). Sabe-se que tanto Fernando Meirelles como Paulo Lins foram processados por Ailton Batata - o Cenoura da ficção -, um ex-traficante de Cidade de Deus, com apoio da antropóloga. ${ }^{8}$ Se ao nos confrontarmos com a relação entre Zaluar e Paulo Lins vimos que dilemas éticos da antropologia eram chamados para justificar a desaprovação de Zaluar pelo romance, no caso do filme, esses dilemas ficaram evidentes demais, dado o enorme sucesso de bilheteria, para permanecerem ocultos em nome da criação ficcional. Tornaram-se uma questão judicial, o que resultou em alteraçôes no romance.

Algo curioso acontece com o destino do filme: com Cidade de Deus, Meirelles alçou-se a coração de Hollywood. ${ }^{9}$ No entanto, ele trilhou um caminho muito mais próximo do cinema europeu ao optar pela não utilização de atores profissionais no filme - ao menos em papéis que representam os moradores do bairro. ${ }^{10}$ Essa forma de construção cinematográfica está diretamente ligada à proposta do neorrealismo italiano - cineastas como Fellini, Rosselini e Pasolini - e pode ser filiada ao cineasta e filósofo francês Robert Bresson e ao Cinema Novo brasileiro. O sucesso comercial de Cidade de Deus e sua proposta não glamurizada com financiamento independente renderam polêmicas sobre a postura ética de Meirelles e Lund e sua capacidade de representar a violência e a pobreza. ${ }^{11}$

Todos esses discursos versam sobre pobreza e violência e referem-se à Cidade de Deus, mas têm especificidades e dialogam com diversas formas de expressão. Antes de buscar possíveis relações entre eles, precisamos enfatizar suas singularidades. Este será nosso intento a seguir.

\section{Sobre a etnografia de Alba Zaluar}

Longe de constituir uma simples importação de modelos teóricos e metodológicos aplicados principalmente nos Estados Unidos, na Escola de
Chicago (Becker, 1996), o estabelecimento de uma antropologia urbana no Brasil tem como base uma série de questionamentos diretos aos modelos estadunidenses. Entre as críticas mais ferozes das elaborações de Park (1979), Wirth (1979), Redfield (1940) e Lewis (1970) estão Ruth Cardoso e Eunice Durham. ${ }^{12}$ As preocupações de Cardoso e Durham têm fundamentalmente um cunho epistemológico e giram em torno de questôes como esta: como poderia uma ciência social marginal, como a antropologia, baseada sobretudo na observação participante, ir além do "ponto de vista do nativo" e construir abordagens que englobassem a sociologia e a economia para escapar de ser uma simples "tradução" dos pontos de vista dos grupos e indivíduos estudados?

Esta pergunta foi proposta pelas autoras ${ }^{13}$ a partir de uma inquietude causada pelos resultados das investigações e das construções teóricas e metodológicas apresentados pela antropologia norte-americana (Cardoso, 2011). Seus trabalhos buscam delimitar a especificidade do desenvolvimento do capitalismo no Brasil, em especial em São Paulo, os efeitos desta ordem econômica nas relações familiares e de trabalho, além de combater estereótipos a respeito da passividade e da ignorância de "favelados".

Embora seu foco seja São Paulo, ${ }^{14}$ Cardoso e Durham foram uma grande fonte de inspiração para Alba Zaluar em A máquina e a revolta. Para dar conta de seus objetivos, Cardoso e Durham se voltam de forma crítica à própria antropologia e seu alcance. Esta ciência especializada em sociedades tribais tinha como base a metodologia de observação participante, que pressupõe uma entrada e um posterior compartilhamento de códigos entre o antropólogo e os "nativos". No entanto, tais códigos, apesar de se constituírem como a matéria-prima da investigação antropológica, não seriam suficientes para dar conta de uma investigação em "sociedades complexas". Seria preciso um diálogo direto com a história, a sociologia e a economia para que se pudessem reconstituir não só a perspectiva dos que enunciam seu discurso mas também processos histórico-sociais de longo prazo, em sua singularidade. A cultura e os códigos de comunicação por ela disseminados seriam múltiplos e atualizados por atividades cotidianas e, sobretudo, construídos na prática. 
Com esta dialética entre o processo histórico e os significados do dia a dia, a crítica de Cardoso incide sobre teses de Oscar Lewis (1970) sobre a "passividade" dos pobres ou sobre sua concepção de cultura como um todo integrado, enfatizada nos estudos sobre a "cultura da pobreza". Para Cardoso, inspirada sobretudo em Leach (1954), a cultura é um jogo capaz de comportar múltiplos canais de expressão e interação. A antropologia urbana seria válida exatamente por aproximar-se das experiências de vida dos "menos favorecidos" pelos meios de comunicação e pelos canais de expressão burocrática. Vemos, assim, que a definição de Roberto Cardoso de Oliveira (1988) de que a antropologia brasileira se definiria a partir de estudos de minorias é também bastante válida para a antropologia urbana do Brasil.

A etnografia de Alba Zaluar em $A$ máquina e a revolta busca reconstituir os discursos de cientistas sociais sobre os pobres na década de 1980, fazendo-lhes uma crítica incisiva a partir de dados empíricos. A primeira tarefa: aproximar-se de um conjunto habitacional estigmatizado como um dos lugares mais violentos do Rio de Janeiro, segundo os jornais de então, e ouvir as pessoas que ali vivem faz com que a guerra cotidiana dos jornais seja aos poucos vista a partir de certas particularidades e outras facetas. O foco de Zaluar, portanto, não é somente uma reconstituição do tráfico e de seus conflitos, mas também a vida cotidiana e seus diversos significados. $\mathrm{O}$ principal alvo da autora são as construçôes a respeito de um povo passivamente controlado por negociaçóes políticas clientelistas, incapaz de transformar sua vida por meio da participação democrática e associativa.

A fim de fornecer mais subsídios para a análise dessa etnografia, vamos ressaltar alguns pontos do debate. Segundo Zaluar, as interpretações de DaMatta (1983), inspiradas na sociologia de Louis Dumont, fazem uma aproximação equivocada entre Brasil e Índia. O diagnóstico de DaMatta, de que a sociedade brasileira não seria nem moderna nem tradicional, visa combinar os dois tipos de sociedade estudados por Dumont, a indiana, de tipo holístico, e a ocidental, de tipo individualista. Zaluar rejeita tal diagnóstico afirmando que os pobres brasileiros não se sentem culpados pela própria po- breza, como ocorre na Índia. Zaluar, então, interpreta o samba como um discurso crítico a respeito do cotidiano:

No samba, os trabalhadores se divertem e aprendem uma outra experiência do mando e do poder, esta bem mais próxima deles e bem melhor por eles controlada. No samba, os vizinhos discutem formas de autoritarismo, da violência, da democracia e da liberdade. [...] Nele, a crítica, embora seguindo o curso velado das manifestaçôes não legitimadas como ideológica ou politicamente importantes, ou valendo-se das metáforas, analogias, subterfúgios das manifestações vigiadas ou reprimidas, continuou a ser exercida, apesar de tudo (Zaluar, 2000, p. 211).

O samba é somente uma das portas de entrada na etnografia de Zaluar. Mas é importante, pois tenta colocar a questão da especificidade da desigualdade social brasileira em outros termos, distantes dos de DaMatta. Como vimos, o foco de Zaluar está no cotidiano. A autora interpreta a violência através dos símbolos associados à construção da masculinidade. Crítica dos modelos simplistas que abordam a relação entre desigualdade social e violência, ela recorrerá a uma frase constantemente utilizada pelos moradores de Cidade de Deus quando, numa discussão, uma das partes acreditava não ter sido tratada com o devido respeito: "não fala assim comigo que eu sou homem". Assim, a questão da violência também ganha contornos distintos e passa a estar atrelada à identidade masculina.

Para entender a construção da identidade dos bandidos, Zaluar recorre à análise do discurso. Os trabalhadores eram vistos como otários (Goldstein, 2003), pois não teriam recompensas materiais tão boas quanto as deles. Os bandidos podiam correr riscos justamente por causa dos símbolos associados à masculinidade. Já os trabalhadores, segundo Zaluar, possuíam uma ética do provedor - seu orgulho estava em conseguir manter sua família. Os dados quantitativos produzidos por Zaluar quase sempre retratam famílias nucleares, o que provaria que "desequilíbrios" ou "desestruturação" familiar não seriam a melhor forma de explicar a entrada de jovens no crime organizado. 
Para alguns jovens, o trabalhador é um escravo que trabalha de segunda a segunda por irrisórios salários, um escravo que se submete a patrões e chefes autoritários que o humilham com ordens ríspidas. Por isso mesmo não podem ter por ele a admiração que sentem pelos que se negam à árdua rotina, à exploração e que se revoltam. Seus modelos e heróis são outros. $\mathrm{Na}$ falta de um movimento operário forte de onde saiam líderes trabalhadores com fama, eles se voltam para os simpáticos malandros de outrora, hoje desaparecidos, e os armados bandidos, hoje em franca proliferação (Zaluar, 2000, p. 156).

Os debates marxistas presentes em $A$ máquina e a revolta não se circunscrevem, no entanto, a uma influência uspiana. Eles também são fruto do exílio de Zaluar na Inglaterra, durante a ditadura militar. A influência da escola de Manchester pode ser vista pelo uso extensivo do conceito de redes sociais, numa crítica ao que Zaluar chamaria de "marxismo pesado", como o que era praticado no Brasil de então (Zaluar, 2005).

O período uspiano de Zaluar é caracterizado por ela como uma troca intelectual intensa, marcada pelo diálogo com Teresa Caldeira e José Guilherme Magnani, seus colegas, e por certa solidão na metrópole. Às suas preocupações críticas se somaria posteriormente a contribuição mais duradoura de seu trabalho: a abordagem do crime organizado a partir de uma perspectiva comparada (especialmente com a máfia italiana), que leve em conta aspectos como as intersecçóes entre as identidades de gênero, classe e raça ${ }^{15}$ (Zaluar, 2005).

A qualquer leitor de $A$ máquina e a revolta, ficam marcados alguns tropos antropológicos clássicos. Zaluar não menciona um trabalho etnográfico coletivo, e o início do livro - "imagine-se estacionando seu carro particular na rua de um bairro de pobres..." - reinventa um tropo malinowskiano. Mas ao contrário da etnografia clássica, Zaluar busca "exotizar" os moradores do bairro em relação aos jornais, que retratavam o bairro como um dos mais violentos do Rio de Janeiro de então. Após sua chegada e gradual aceitação por parte dos moradores, Zaluar logo enfatiza certa calmaria presente no conjunto habitacional. Este procedimento, assim, transforma-se em uma forma de estranhamento e ganha status importante para entender os universos simbólicos presentes no bairro. É curioso o fato de que Zaluar parece o tempo todo trabalhar solitariamente; e só sabemos do trabalho conjunto com Paulo Lins na edição do romance. Mesmo as dificuldades de pesquisa enfrentadas por Zaluar são textualizadas somente como um confronto com a alteridade no início da pesquisa.

A seguir, analisaremos o romance ${ }^{16}$ e as inspiraçôes literárias de Paulo Lins. Se a etnografia constrói seu discurso através do trabalho de campo, o romance dialoga com a tradição literária.

\section{Cidade de Deus a a polifonia etnográfica}

Paulo Lins afirma que para a elaboração de Cidade de Deus tomou "empréstimos" da obra de José Lins do Rego e Fiódor Dostoiévski, ${ }^{17}$ o que certamente é relevante em seu processo de criação: a construção literária das histórias de vida dos moradores de Cidade de Deus está vinculada a essas apropriações. Sem isso em mente, a interpretação do romance perderia densidade. Paulo Lins se utiliza de um espaço autoral, produzido pela literatura, para enfatizar sua construção e distanciar o romance da "realidade". É a labuta estética que lhe permite problematizar as fronteiras entre "realidade" e "ficção" presentes em Cidade de Deus. Não pretendemos realizar aqui uma crítica genética desse processo, mas apenas chamar atenção para aspectos importantes do romance, assim como mostrar as fontes de inspiração do autor.

O romance social dos anos de 1930, segundo Bosi (1994), dialogou diretamente com as transformações sociais e políticas de então e criou novas formas de experimentação artística. Herdeiros de uma literatura expressa a partir da linguagem coloquial, essa literatura explorou o potencial crítico da cultura popular, assim como o racismo, o nazifascismo, o nacionalismo e o socialismo (Paiva, 2010). O romance regionalista ganhou novas formas de experimentação com autores como Jorge Amado, José Lins do Rego e Graciliano Ramos. Caracterizados pela retomada do naturalismo e recuperando de forma crítica a herança realista do século XIX, as 
obras produzidas nessa década não se deixam levar por um realismo ingênuo, que produziria uma narrativa impessoal; ao contrário, figura ali uma maior problematização da posição do narrador.

Críticos literários de Fogo Morto, como Benjamin Abdala Jr. e Mário de Andrade, reconhecem o orgulho, associado à ideia de masculinidade, como o sentimento norteador das principais personagens do romance. Cada uma das três partes da obra tem uma personagem masculina como figura central. Mestre José Amaro, por exemplo, personagem principal da primeira parte, faz reflexões sobre a capacidade de combater e dobrar os demais pela violência como forma de avaliar a honra das personagens masculinas com os quais se compara. Tanto a etnografia de Zaluar como o filme de Meirelles e Lund também discutem a conexão entre honra, violência e masculinidade. Na primeira, a análise das letras dos sambas que versam sobre Mané Galinha mostra como sua conversão ao crime tem a ver com o desejo de lavar sua honra, o que o diferencia dos outros bandidos. Este mesmo retrato é intencionalmente construído no filme. ${ }^{18}$

O racismo é outro tema presente tanto em Fogo morto como em Cidade de Deus, o que não quer dizer que Lins tenha se pautado apenas neste romance para construir sua narrativa sobre os conflitos raciais (Schwarz, 2001). O cenário desenhado por José Lins do Rego é de um nordeste decadente, no período pós-abolição. A evocação de um cativeiro inexistente é um recurso imaginário para manter os negros "em seu lugar". Em Cidade de Deus, os conflitos raciais manifestam-se em situações cotidianas com frequentes referências à honra e à masculinidade dos trabalhadores, dos bandidos e dos policiais, em um contexto que perpassa toda a obra, como já referido: as disputas entre migrantes nordestinos e os negros da comunidade.

Ao contrário de Fogo Morto, cujas personagens ocupam um lugar muito evidente na narrativa, Paulo Lins propõe um paradigma polifônico na construção de Cidade de Deus. Isso decerto está ligado ao segundo nome de quem Paulo Lins afirma ter "roubado" partes de seu romance: Dostoiévski. Como mostra Mikhail Bakhtin (1997), a obra de Dostoiévski está fundamentada na multiplicidade de vozes que não estão subsumidas às vozes do autor (Wildhagen, 2007). Uma análise crítica que privilegie apenas as personagens principais e suas concepções filosóficas não se sustenta aqui, de acordo com Bakhtin. Tampouco é o enredo o princípio orientador da construção narrativa do romancista russo; a ação das personagens ocorre em diversos planos e sequer conduz aos conflitos da trama. A leitura de Cidade de Deus causa uma impressão muito semelhante. Com efeito, o próprio autor já admitiu a influência decisiva de Dostoiévski em sua obra ficcional (Rocha, 2007).

Quando os conflitos, na trama de Cidade de Deus, envolvem personagens femininas, ora vêm acompanhados de uma incisiva crítica à ação policial, ora se deslocam para a esfera da afetividade. Parece não haver muito espaço para as mulheres no universo do crime, o que reforça a imagem de um ambiente fortemente masculino. ${ }^{19}$ No entanto, é preciso ressaltar que o controle da sexualidade e do comportamento das mulheres no livro é um dos componentes centrais da identidade masculina, ${ }^{20}$ $\mathrm{e}$ isso efetivamente coloca as personagens femininas dentro daquele universo. As mulheres chegam a desempenhar papéis extremamente importantes, como o de orquestrar a saída de personagens do mundo do crime para ingressar no mercado de trabalho, como acontece com a personagem Alicate.

Voltando à etnografia, é interessante notar na análise aqui empreendida que estamos diante de um paradigma textual desdobrado em dois: o paradigma da etnografia polifônica e o do romance polifônico. Não há dúvida de que o segundo já fazia parte da tradição literária ocidental e foi adotado na concepção de Cidade de Deus. A etnografia polifônica, por sua vez, estabeleceu-se, sobretudo, nos anos de 1980, nos Estados Unidos. É responsável por uma problematização radical da escrita etnográfica, levando antropólogos a se aproximarem da forma literária, particularmente da polifonia do romance dostoievskiano (Clifford, 1998; Marcus e Cushman, 1982). ${ }^{21}$ Dessa perspectiva é que o romance de Paulo Lins poderia ser utilizado pela antropologia: não necessariamente como um modelo a ser copiado, mas como uma forma de textualização da uma experiência interessante, no sentido de que cria um diálogo entre a polifonia e o romance brasileiro da década de 1930 (Ribeiro, 2000). 
A problematização de Ruth Cardoso da escrita etnográfica, realizada em paralelo com a construção de novos paradigmas nos Estados Unidos, como lembra Teresa Caldeira ${ }^{22}$ (Cardoso, 2011), está mais preocupada em chamar atenção para uma relação de poder existente entre o antropólogo e seus interlocutores que em analisar a experiência etnográfica para compreender como se estruturam a autoridade e a legitimação da observação antropológica participante. Não pretendemos aqui mostrar as diversas formas de produção da autoridade etnográfica, mas analisar o caso particular da estruturação dos discursos sobre a Cidade de Deus. No entanto, a questão do paradigma etnográfico polifônico não é sequer colocada como uma possibilidade. Só podemos interpretar a etnografia de Zaluar a partir desse prisma quando situamos seu trabalho ao lado do romance de Paulo Lins e do filme de Fernando Meirelles e Katia Lund.

No confronto de perspectivas, vimos que há posições divergentes em relação às representações da pobreza e da violência. Por exemplo, se na etnografia de Zaluar a família não poderia ser responsável pela entrada no crime e pela carreira criminosa dos jovens, no filme de Meirelles e Lund, a desestruturação familiar é a única explicação que sustenta a maioria das histórias pessoais de criminosos, sobretudo de Zé Pequeno, personagem de grande relevância no filme no caso específico, ausência da figura paterna. De fato, os diretores alinham-se a uma longa tradição cinematográfica que assim justifica as causas de uma trajetória criminal - entre muitos, o filme Marnie (1954), de Alfred Hitchcock, é um bom exemplo dessa orientação. O romance de Paulo Lins, por sua vez, alinha-se não só com o gênero policial da produção cinematográfica mas também com o naturalismo literário brasileiro da década de 1930. Exemplo disso é a maneira como Marreco é apresentado:

Marreco foi criado no morro da Cachoeirinha. Quis ser bandido para ser temido por todos, assim como foram os bandidos do lugar onde morou. Os bichos-soltos botavam tanta moral que o medroso de seu pai não tinha nem coragem de olhar nos olhos deles. Gostava do jeito dos malandros falarem, da forma como se vestiam (Lins, 1997, p. 29).
Segundo Comaroff e Comaroff (2010), a análise do contexto de produção cultural - neste caso, antropológica, literária e cinematográfica - remete a uma imaginação histórica e antropológica. Os referentes utilizados muitas vezes são os mesmos, como prova o caso da masculinidade, mas o que os diferencia é o contexto. O que as três visões de $\mathrm{Ci}$ dade de Deus mostram é algo que geralmente está implícito: o acordo tácito entre leitores e autores é fundamental para a classificação entre "ficção" e "não ficção" (Searle, 1975). Poderíamos encorajar uma leitura política do romance, a qual teria de revelar as diversas formas de construção das personagens que incorporam a figura do bandido no discurso de Lins. De outra forma, tal leitura estaria fadada ao fracasso.

É preciso lembrar que a adaptação de um romance com múltiplos planos de ação e sem uma personagem principal foi o desafio do roteirista Bráulio Mantovani e dos diretores Fernando Meirelles e Katia Lund. A seguir, analisaremos de forma sucinta a proposta cinematográfica de Cidade de Deus.

\section{O filme: fotografia, literatura, cinema}

Salta aos olhos de qualquer intérprete do filme Cidade de Deus que não há referência à etnografia de Alba Zaluar. Como vimos, $A$ máquina e a revolta não toca em temas amplamente abordados no romance de Paulo Lins. Na etnografia, há somente uma referencia à presença negra no bairro, justamente quando a autora utiliza a fotografia como ferramenta de pesquisa para observar as representaçōes dos próprios moradores de Cidade de Deus sobre sua aparência e sobre seus juízos estéticos. Em contrapartida, Lins constrói um cenário carregado de conflitos raciais. Este seria, a nosso ver, um ponto de partida interessante para análise do filme e de sua intertextualidade, pois, segundo o próprio Meirelles, a etnografia de Zaluar não foi consultada para a realização do filme. ${ }^{23} \mathrm{O}$ confronto entre Zaluar e Lins diz respeito à maneira de retratar o bairro. Zaluar chama atenção para as implicações éticas desse retrato. $\mathrm{O}$ exemplo dos confrontos raciais apenas demonstra o alcance da etnografia e dos problemas levantados pela antropóloga. 
A fotografia que tinha servido à autora como uma ferramenta de pesquisa - em um contexto de alteridade antropológica, seria uma forma de problematizar o que se toma, a princípio, como insignificante $-{ }^{24}$ e o exemplo das representaçōes raciais dos moradores de Cidade de Deus é marcante nesse sentido. No filme, por outro lado, o narrador da história, Busca-Pé, usa a fotografia como uma forma de projetar o "extraordinário", isto é, como repórter fotográfico iniciante, ele registra para a imprensa os bandidos e a violência de Cidade de Deus, não como um voyeur inocente (Xavier, 2006), tampouco como uma personagem que busca a todo custo distanciar-se dos bandidos. Mas se na narrativa ficcional ele não é uma personagem predominante, ${ }^{25}$ no filme, é alçado, através da fotografia, ao papel de narrador. ${ }^{26} \mathrm{O}$ fio condutor da personagem se faz, pois, pela relação entre fotografia e cinema. Com o trabalho de Busca-Pé na imprensa, busca-se mostrar o caráter "oculto" do fazer fotográfico: o trabalho mesmo do fotógrafo é desvelado a partir do "realismo" no cinema ${ }^{27}$ (Sontag, 2004).

Para avançar na análise das particularidades do filme, recorremos à polêmica deflagrada por Ivana Bentes (2007) a respeito da ética envolvida no cinema brasileiro a partir de Cidade de Deus. Segundo ela, a representação dos sertôes e das favelas no cinema nacional experimentou a partir anos de 1990 uma mudança radical em relação à proposta do Cinema Novo das décadas de 1960 e $1970,{ }^{28} \mathrm{em}$ especial de seu principal teórico, Glauber Rocha (1963). Filmes como Vidas secas (1963), de Nelson Pereira dos Santos, e Deus e o diabo na terra do sol (1964), de Glauber Rocha, teriam inventado uma estética crua, com uma câmera na mão, luz natural, sem floreios estéticos, rompendo definitivamente com as convenções narrativas de Hollywood. Para Glauber, posicionar-se contra o exotismo e o paternalismo europeus significava romper com a nostalgia do primitivismo. A "estética da violência e da fome" ensaiada pelo Cinema Novo tinha como lema a frase: "não gozarás com a miséria alheia". Em contrapartida, os filmes pós-1990, incluindo Cidade de Deus, deixam de ter o propósito de "violentar" os sentidos do espectador (Glauber Rocha apud Bentes, 2007) para experimentar os sertōes e as favelas ora como espaço de reconciliação, ora como espaço de "extermínio tranquilizador", ou seja, quando a própria violência do meio determina a execução sumária da população pobre.

No entanto, aquilo que Bentes não aborda em sua análise é o que mais nos intriga. A autora não comenta o contexto histórico de realização dos filmes de Glauber Rocha e Nelson Pereira dos Santos caracterizado, entre outras coisas, pelo apoio estatal da Embrafilme (Empresa Brasileira de Filmes) (Bernardet, 2009) -, desprezando, por outro lado, o marco histórico que foi a extinção dessa empresa pelo governo Collor em 1990. Com efeito, o novo contexto que se formou a partir daí é fundamental para a compreensão do filme de Meirelles e Lund, ${ }^{29}$ e não discuti-lo excluiu da análise de Bentes a possibilidade de uma abordagem empírica sobre a recepção de Cidade de Deus. Nesse sentido, coube a Fernando Mascarello (2004) romper com as elaboraçōes de Bentes, ${ }^{30}$ baseado na ideia de que o espectador não é um sujeito passivo diante da mensagem fílmica, mas está inserido em um contexto de projeção e de "economia de prazeres" (Ribeiro, 2005). Mascarello se volta contra uma tradição crítica, possuidora de capital simbólico, que teria certa autoridade no momento de enunciar seu discurso. A polêmica em torno de Cidade de Deus por parte da crítica abriu as portas para estudos empíricos a respeito de como os espectadores brasileiros encaram os filmes nacionais. Vale lembrar que o filme foi o grande responsável por alargar o público em relação ao romance e à etnografia sobre Cidade de Deus. ${ }^{31}$

Há ainda outros pontos que merecem nossa atenção. $\mathrm{O}$ fato de Fernando Meirelles pôr em cena agentes sociais que não eram atores profissionais ${ }^{32}$ deixa claro que o filme busca um diálogo direto com a construção do cotidiano de Cidade de Deus. Quando acusado por MVBill de reproduzir estereótipos, Meirelles alegou que havia realizado uma espécie de "trabalho de campo" no bairro, aproximando sua equipe dos moradores dali. O retrato daquela comunidade, por isso, foi mais fiel, menos estereotipado, segundo o diretor. É interessante que Meirelles assevere com isso a autonomia do filme em relação ao romance, ou seja, não se trata de uma simples reprodução. Evidentemente o filme tem com referencial o livro, mas a especificidade de sua realização 
foi justamente esse "trabalho de campo", que revelou outras e novas histórias de vida e pode confrontá-las com a narrativa de Paulo Lins. Dessa forma, para a realização do filme, o romance foi confrontado com os relatos dos moradores de Cidade de Deus, acrescentando-se novas histórias e tornando as personagens centrais minimamente "bem representadas" na construção cinematográfica. ${ }^{33}$

O processo de aprendizado dos não atores é descrito por Meirelles a partir de sua rede de relações com o grupo de teatro Nós do Morro, ${ }^{34}$ sediado no Vidigal. De 4 mil inscritos, foram selecionados 200 finalistas que participariam da oficina de atuação (Caetano, 2007). Essa oficina ajudou Meirelles e Lund a testar o roteiro do filme. Quando alguma cena ou fala de personagens era questionada pelos futuros participantes do filme, os diretores reformulavam o roteiro. $\mathrm{Na}$ oficina, eram propostas situações dramáticas que poderiam ter sido vivenciadas no cotidiano do elenco, adensando o vínculo entre roteiro e performance. Antes do longa-metragem, foram ainda realizados, como uma espécie de teste, dois curtas-metragens e um episódio para o especial de Natal da TV Globo, que viria a se tornar a série Cidade dos Homens, levada ao ar entre 2002 e 2005.

O que vale ressaltar, sobretudo, é o fato de que a não utilização de atores profissionais abriu um precedente importante para análise antropológica do cinema. Esse procedimento tem no cineasta francês Robert Bresson sua sistematização (Bresson, 1979; Bernardet, 2009), distanciando seus filmes da indústria cinematográfica de Hollywood. A construção do processo de aprendizado para a atuação no filme, a experiência nas gravações e a possibilidade de ver o filme finalizado, além do caminho aberto para seguir uma carreira profissional, são fundamentais para a análise do elenco de Cidade de Deus. O site do filme ajuda a entender todo esse processo, com ricos depoimentos daqueles que atuaram ali. Leandro Firmino da Hora, que representou a personagem Zé Pequeno, assim descreve sua experiência:

A dona Fátima Toledo gosta de contar que quando comecei a preparar o meu papel de Zé Pequeno, pedi ajuda para ela encontrar em mim mesmo o ódio que precisava encontrar no personagem. [...] Quando eu estava interpretando pensava como o personagem. Queria ter tudo, fixava em mim a sensação de poder.

O Zé Pequeno que realmente existiu era um cara desumano, que matava sem dó, sem piedade e desde menino. É uma história verídica, os moradores contam até hoje histórias dele. [...]

Eu o vejo como um ser humano normal, mas que por ironia do destino entrou no caminho errado.

O que vemos aqui é um amálgama da experiência real com a experiência de interpretação. $\mathrm{O}$ efeito de realidade do filme já se faz presente na seleção do elenco. Entender Zé Pequeno pela performance no cinema significa "fixar a sensação de poder" e a "desumanidade" da personagem. Para conseguir entrar na pele de um "cara desumano" como Zé Pequeno, o ator teve que, antes, entendê-lo como um ser humano normal.

O processo de realização de Cidade de Deus levou Meirelles e sua equipe à criação do grupo Nós do Cinema, que se tornou posteriormente uma ONG, servindo de ponte entre os "não atores profissionais" que atuaram em Cidade de Deus e os diretores. A produtora dirigida por Meirelles - $\mathrm{O} 2$ Filmes - tem como um dos objetivos o fomento de um cinema brasileiro comercial e mantém ligação direta com a publicidade e com a formação de mão de obra especializada para o mercado audiovisual. Se a preocupação com o público é uma marca da carreira audiovisual de Fernando Meirelles, desde sua entrada na TV, passando pela publicidade e pelo cinema, a competição pelas salas de cinema não poderia deixar de ser um aspecto relevante em todo esse processo (Bernardet, 2009). Com a criação da ONG, Meirelles e Lund buscaram reafirmar um compromisso ético com os atores sociais envolvidos na realização de Cidade de Deus.

Em suma, esta discussão revela quão intrincada é, em termos de narrativa, a relação entre "realidade" e "ficção"35 (Guynn, 2006). O confronto perspicaz entre as diversas formas de narrar deve atentar para as particularidades de produção das narrativas e suas formas de entrecruzamento com o cotidiano 
das personagens representadas. O trabalho etnográfico de Edir Mello (2010), que retornou às narrativas dos moradores do bairro em um momento posterior às imagens criadas tanto pela etnografia de Zaluar, como pela prosa de Paulo Lins e o filme de Meirelles e Lund, mantém viva a polêmica associada às muitas Cidades de Deus e às diversas formas de produção e recepção das mensagens científicas e artísticas. A análise das controvérsias é uma maneira de pensar as formas de construção discursiva sobre determinada realidade, desvendando a diversidade simbólica presente tanto nas obras aqui discutidas como na vida cotidiana de Cidade de Deus.

\section{Consideraçóes finais}

Como afirma Cardoso: "Interpretar é, portanto, encontrar uma maneira de penetrar nas narrativas sem perder de vista a estreita relação com o sujeito e a situação que as originaram" (2011, pp. 168-169). Com este trabalho buscamos compreender como foram construídos os discursos em seus contextos de enunciação.

Assumindo a proposta metodológica de Ruth Cardoso, as narrativas antropológica, novelística e cinematográfica sobre o bairro foram interpretadas tanto a partir de suas lógicas internas como por seus distintos contextos e sujeitos envolvidos. Questionar as diferentes representações contidas nesses discursos significa compreender os posicionamentos a respeito das questóes sociais: a interpretação não está livre de uma investigação sobre as consequências políticas dos discursos.

A questão racial, por exemplo, exige maior cuidado. Não problematizada em toda sua complexidade em $A$ máquina e a revolta, ela surge com bastante força no romance e no filme. Nossa opção por evidenciar isto através da relação entre Ruth Cardoso e Eunice Durham buscou seguir um fio teórico comum entre os estudos a respeito de questôes étnico-raciais e as investigações antropológicas com populações urbanas, dialogando, pois, com a Escola de Chicago e com a sociologia estadunidense (Cardoso, 2000; Chalhoub, 1989; Pinto, 2008). Os estudos de relações raciais e as investigações antropológicas urbanas travam diálogos que podem ser teórica e metodologicamente articulados. No entanto, mesmo que tenham trabalhado em boa parte de sua trajetória acadêmica com movimentos sociais urbanos, as autoras não abordaram o movimento negro.

Acreditamos que $A$ máquina e a revolta se detém no estudo das organizações populares, propondo um debate com Roberto DaMatta e, sobretudo, com a história social. ${ }^{36}$ Outra hipótese para uma interpretação sobre o horizonte de possibilidades que suscitou a perspectiva antropológica elaborada por Zaluar tem a ver com a proposta da construção do bairro como um conjunto habitacional destinado a abrigar moradores de diversas favelas, em um contexto de ações governamentais para a extinção de favelas no Rio de Janeiro (Valladares, 1979; Gay, 1994; Perlman, 2010). A heterogeneidade dos grupos que foram alocados para lá pode ter atraído a atenção da autora para investigar a organização social de Cidade de Deus nos anos de 1980.

Por outro lado, a partilha do material etnográfico bruto entre Zaluar e Paulo Lins permitiu uma interpretação "ficcionalizada" dos discursos dos moradores, tendo por base referências literárias como José Lins do Rego e Fiódor Dostoiévski. Essa partilha foi, como vimos, fonte de debate público entre Zaluar e Lins sobre os limites éticos do romance. Acreditamos que as mudanças no romance tiveram o intuito de afastar o leitor do atual cotidiano do bairro. Mas, além disso, está subjacente à construção do romance o diálogo com certa tradição da literatura brasileira - o romance realista da década de 1930 - e com a polifonia da obra do escritor russo, o que não pode ser desprezado para entender o romance Cidade de Deus.

As representações de Cidade de Deus em cada uma da obras aqui analisadas são complexas, abrangendo desde questionamentos clássicos marxistas a respeito da autonomia relativa da classe trabalhadora até questôes sobre sexualidade e construção da ideia de masculinidade. As diversas vozes que aproximamos neste trabalho interpretam a vivência social do bairro a partir de pontos de vista específicos e defendem as fronteiras de suas narrativas tendo por base tal peculiaridade, o que está diretamente ligado ao campo de atuação em que se situam Zaluar, Lins e Meirelles: a antropologia, a 
literatura e o cinema, respectivamente. A questão da desigualdade e da masculinidade, a problemática do romance social e a relação entre fotografia e cinema são exemplos evidentes do diálogo entre essas três áreas, sem que seja preciso hierarquizar as propostas de cada trabalho. Se a capacidade de narrar a própria experiência foi posta em questão por Walter Benjamin ${ }^{37}$ (1986) ao assumir a difusão da imprensa e do romance como formas de contar histórias distanciadas da oralidade, é justamente em nome dessa aptidão ${ }^{38}$ que reivindicamos um lugar para nossa análise dos discursos articulados sobre o bairro Cidade de Deus.

\section{Notas}

1 Estar atento a estas nuances é de alguma forma se aproximar da perspectiva sociológica elaborada por Bourdieu.

2 É ainda por possuírem uma história comum que as obras analisadas devem ser perspectivadas como possuidoras de uma relação histórica intertextual, como se verá a seguir.

3 Assim Zaluar (2000, p. 166) descreve a ética dos bandidos: "Como consumidores, os bandidos não desenvolvem um estilo próprio de vida em bandos fora-da-lei, mas almejam os bens que a sociedade de consumo lhes oferece. [...] Tampouco tem 'um programa de restauração da ordem tradicional das coisas como deveriam ser', como supostamente teriam os bandidos sociais ou os camponeses fora-da-lei (Hobsbawn, 1969). Não são reformistas, nem revolucionários. Não lutam por relações mais justas entre ricos e pobres, fortes e fracos. Suas ações podem ser interpretadas uma como revolta individual contra as condições adversas sob a forma de recusa ao trabalho destinado à população pobre, assim como a participação num dos mais rendosos comércios que se tem no mundo capitalista. Mas de pobres revoltados a membros menores de uma gigantesca rede de crime organizado, estes bandidos pobres têm um longo percurso a fazer e repetem em si mesmos todas as ambiguidades do bandido anotadas por Hobsbawn”.

4 Este é um dos principais problemas das teses que têm como foco a análise literária de Cidade de Deus: a ausência de uma análise aprofundada dos conflitos raciais presentes no romance. $\mathrm{Na}$ dissertação de Rocha (2007), os moradores de Cidade de Deus são caracte- rizados como "retirantes", "migrantes", "lumpenproletariado", mas em nenhum momento, apesar de sua análise se apoiar em um referencial marxista, a transição da escravidão para o trabalho livre é ressaltada (e, portanto, a construção dos conflitos raciais posta em análise). Já na análise realizada por Quitério (2012), mesmo que Florestan Fernandes seja citado, as relações raciais tampouco se constituem como o seu foco.

5 Entrevista de Paulo Lins concedida a Heloísa Buarque de Hollanda, disponível em http://www.heloisabuarquedehollanda.com.br/?p=712.

6 Em uma entrevista ao jornal Folha de S. Paulo, Alba Zaluar, em 12 de junho de 2004, afirmou: "Há uma série de impropriedades no romance. Nunca existiu, por exemplo, aquele bando de meninos ainda com dente de leite dando tiro nas pessoas. E é muito sério porque cria uma imagem sobre as crianças que vivem nesses locais que não é verdadeira. A própria história de Zé Pequeno é contada como se ele já tivesse nascido ruim. É uma volta à teoria do criminoso nato que, do ponto de vista da criminologia, está completamente superada”.

7 Em entrevista, Zaluar (2005) afirma: "A ideia de nosso projeto no Nupevi é ultrapassar a argumentação simplista do determinismo econômico que faz com que se pense que toda a questão da violência e da criminalidade possa ser explicada pela pobreza e pela desigualdade [...] fizemos um levantamento na Cidade de Deus e concluímos que só $2 \%$ da população de lá está envolvida com o crime. Como explicar que a maioria das pessoas não se envolveu com o tráfico? Certamente tem algo mais aí."

8 Segundo Caetano (2007, p. 204), em uma entrevista com Meirelles, o diretor afirma: "Estimulado pela antropóloga [Alba Zaluar], um morador de CDD [Cidade de Deus] resolveu nos processar, argumentando que seria o Sandro Cenoura (personagem do Matheus Nachtergaele). Mesmo não havendo nenhuma coincidência entre as cenas do nosso Cenoura e a vida do referido morador. Paulo Lins sofreu muito com a violência e o despropósito das acusações e acabou inclusive trocando os nomes das personagens na nova edição que fez do livro, para evitar novos problemas".

9 O alcance da mensagem cinematográfica comercial levanta questões importantes para a antropologia no que concerne ao alcance da mensagem antropológica. Muito mais restrita ao mundo acadêmico, essa mensagem muitas vezes só deixa a academia em questões judiciais, nos jornais ou via demandas sociais (como na atuação de movimentos sociais ou na construção de postos públicos em que atuam antropólogos). 
10 O trabalho de Ribeiro (2003) discute os problemas e as consequências de Cidade de Deus para seus moradores. As justificativas de Meirelles e Paulo Lins são reunidas para uma análise do entrelaçamento dos discursos do filme e do livro Cidade de Deus. Uma análise semelhante pode ser encontrada no segundo capítulo da etnografia realizada por Mello (2010).

11 Uma dessas polêmicas envolveu o debate entre Paulo Lins e Fernando Meirelles em torno da personagem Zé Pequeno. As mesmas críticas feitas por Zaluar a Lins foram feitas por Lins a Meirelles. Segundo Lins (apud Caetano, 2007), Zé Pequeno deveria ser retratado com alguma justificativa para a sua violência e não como um "criminoso nato".

12 Para uma revisão da trajetória intelectual de Eunice Durham, ver o prefácio de Peter Fry à coletânea de artigos de Durham intitulada Dinâmica da cultura: ensaios de antropologia (2004). A própria Durham faz um esforço de reflexão sobre sua trajetória de pesquisas na introdução dessa obra.

13 O horizonte intelectual em comum entre Eunice Durham e Ruth Cardoso é aqui analisado não só por sua produção conjunta, mas também por sua proximidade e parceria intelectual. É preciso lembrar que ambas foram estudantes de mestrado na cátedra de Egon Schaden e que Eunice Durham, por ter ficado no Brasil durante toda a ditadura, foi orientadora de doutorado de Ruth Cardoso. Ambas também trabalharam juntas na USP durante boa parte de sua vida acadêmica (Cardoso, 2011).

14 Contamos aqui uma história concisa dos debates entre vários grupos que contribuíram para o estabelecimento da sociologia e da antropologia urbana em São Paulo. Para uma contribuição mais detalhada de outros debates nesse campo, ver Arantes (2009).

15 A este respeito, Zaluar afirma (2005): "Eu já tentei refletir um pouco sobre isso no memorial de professora titular e, antes, de professora docente na Unicamp, tentando compreender, porque para mim é um mistério, um enigma. Por que é que eu, uma moça da Zona Sul, que gostava de praia, de samba, de festa e de projetos políticos consequentes, que podiam ser levados adiante através de uma luta de outro tipo, fui acabar especialista em violência? Acho que foi um pouco resultado da minha tentativa de entender o outro. $\mathrm{O}$ outro, no caso, é o homem. Eu acho que a mulher é um outro... É um bicho diferente".

16 Utilizamos, sobretudo, a primeira edição do romance. A razão disso é o fato de que a segunda edição, lançada depois do filme, sofreu pressões dos editores e das ques- tões judiciais levantadas com a primeira edição. Não acreditamos que Paulo Lins estava "mais livre" para criar sua obra quando foi publicada pela primeira vez, mas vemo-la como um tipo de "experiência textual" que está interconectada com a etnografia e o filme, em uma relação intertextual histórica.

17 Ver a entrevista de Paulo Lins concedida a Heloísa Buarque de Hollanda. Disponível em http://www. heloisabuarquedehollanda.com.br/?p=712.

18 Para uma abordagem antropológica da masculinidade e sua relação com a violência, ver Welzer-Lang (2001).

19 A presença feminina no universo do crime estará mais marcada na série de TV "Cidade dos Homens".

20 Flávia Péret (2009) aborda a representação sobre as subjetividades travestis nos romances Cidade de Deus, de Paulo Lins, e Estação Carandiru, de Dráuzio Varella. Vale ressaltar que a autora desliza, em muitos momentos de sua análise, em uma visão biologizante tanto das mulheres como das travestis, visão desafiada pelo referencial teórico que ela mesma utiliza: a teoria queer e sobretudo o trabalho de Judith Butler.

21 Há um extenso debate sobre os limites e as possibilidades da escrita etnográfica na antropologia contemporânea. Para que o leitor tenha mais subsídios em compreender diferentes posiçóes, ver Rabinow (1977), Visweswaran (1997) e Ho (2008).

22 Caldeira se refere em especial a um texto de Ruth Cardoso, chamado "Notas para discussão", apresentado no Seminário de Análise do Discurso, no Departamento de Ciência Política da USP, em 1979 (Cardoso, 2011). O argumento de Caldeira está voltado para a convergência da problematização da escrita etnográfica, no Brasil e nos Estados Unidos, entre 1970 e 1980. Ruth Cardoso utiliza o trabalho de Michel Foucault para construir uma perspectiva que englobe as relações de poder entre antropólogos e seus interlocutores, o contexto em que o trabalho de campo antropológico foi realizado e o posterior trabalho de interpretação antropológica (a escrita etnográfica).

23 Isto seria um ponto de partida para a análise, mas não quer dizer necessariamente que o contato com a etnografia de Zaluar mudaria a abordagem dos diretores em relação às questōes raciais no filme. Para uma análise rica e detalhada dos debates envolvendo a recepção do filme Cidade de Deus pelos moradores do bairro, assim como a admissão de Fernando Meirelles de que não teve acesso à obra de Zaluar, ver Mello, (2010). Nesta polêmica, Zaluar ainda afirmaria, em uma entrevista, em 2004: "tenho certeza que leram o meu livro” (Zaluar, 2005). 
24 "Suas representações sobre a condição de pobre - 'ô menino, saí daí que você tá todo sujo. Vão pensar que pobre não toma banho' - seus preconceitos raciais 'preto queima fotografia' - eram estimulados pelas fotos" (Zaluar, 2000, p. 21).

25 Vale lembrar que o romance e o filme se diferenciam radicalmente quando tratam do tema da fotografia. No primeiro, não há menção ao tema e à trajetória de fotógrafo de Busca-Pé; no segundo, a relação entre Busca-Pé e os bandidos se faz pela fotografia.

26 Busca-Pé é uma personagem marcante do filme de Meirelles e Lund também por romper o ciclo de vingança que norteia tanto a trama do filme como a identidade dos bandidos. Lembramos que, para fins dramáticos, Zé Pequeno é o responsável pela morte do irmão de Busca-Pé (o que está em "discordância" com o livro de Paulo Lins). Ao fotografar Zé Pequeno morto e conseguir um trabalho em um jornal, Busca-Pé de alguma forma, pela fotografia, sente-se confortado.

27 Para uma outra interpretação sobre a questão do olhar no filme Cidade de Deus, ver César (2007).,

28 Segundo Bentes (2007), exemplos dessa mudança podem ser encontrados em filmes contemporâneos como Central do Brasil (1998), de Walter Salles, Eu, tu, eles (2000), de Andrucha Waddington, e Cidade de Deus (2002), de Fernando Meirelles e Katia Lund. A análise da autora contrasta tais filmes com Vidas secas (1963), Rio 40 graus (1955) e Rio Zona Norte (1957), de Nelson Pereira dos Santos, e Deus e o diabo na terra do sol (1964), Barravento (1961), Câncer (1972) e O dragão da maldade contra o santo guerreiro (1968), de Glauber Rocha.

29 Criada na década de 1960, a Embrafilme faz parte de uma série de intervençóes estatais para alavancar a produção cinematográfica brasileira. A princípio, a Embrafilme financiava produções, funcionando como um banco para quem produtores e diretores deveriam pagar as dívidas da produção cinematográfica. A partir de 1973, passa a coproduzir os filmes brasileiros, assumindo, então, um papel ativo, sendo corresponsável pelo lucro dos filmes. Em 1977, assume também a distribuição da produção nacional. A empresa foi extinta durante a onda de privatizações e cortes de gastos do governo Collor (1990-1992). Esta virada foi fundamental para uma mudança nas formas de financiamento da produção cinematográfica brasileira nos anos de 1990, que passou a contar com o incentivo fiscal oferecido pela Lei Rouanet. Vozes de cineastas e críticos de cinema ressaltaram as características peculiares da intervenção estatal na produção cinematográfica brasileira. Para conhecer esse debate, ver Bernardet (2009).
30 Cabe ressaltar, em contrapartida, que o trabalho de Bentes é um dos poucos que enfrenta a questão da mediação. Exemplo disso é sua afirmação de que os "intelectuais da favela", como Paulo Lins e MVBill, não necessitam de mediadores para expressar-se.

31 Ainda segundo Mascarello (2004), é preciso reconhecer que há certa escassez de investigações sobre os diversos públicos do cinema nacional, em uma perspectiva que conceda ao espectador papel ativo na reinterpretação da mensagem fílmica.

$32 \mathrm{Na}$ etnografia sobre Cidade de Deus realizada por Edir Mello (2010), a Cufa (Central Única das Favelas) aparece como uma instituição central na canalização das aspiraçôes dos jovens de Cidade de Deus para que tenham acesso a um campo de atuação considerado das classes médias e altas, a saber, o audiovisual. O trabalho de Mello discute amplamente questôes como as do estigma socioespacial e das trajetórias de mobilidade ascendente presentes na Cidade de Deus contemporânea.

33 A cena em que Zé Pequeno obriga Mané Galinha a ficar nu, no baile de despedida de Bené é um exemplo das histórias recolhidas no "trabalho de campo" antropológico da equipe de Meirelles. Essa história ganha relevância especial por não estar no livro, e é crucial para a nossa interpretação, já que coloca o filme na encruzilhada polifônica dos modos de representar as histórias daquela comunidade (ver extras do DVD de Cidade de Deus).

34 Hoje, a ONG criada a partir do filme denomina-se Cinema Nosso. Ver http://www.cinemanosso.org.br/site/.

35 Bastam dois exemplos para verificar tal fato: primeiro, a oficina realizada por Meirelles e Lund para treinar os não atores buscava no discurso dos agentes sociais, selecionados para a preparação e aprendizado artísticos, uma aproximação com as situações reais vivenciadas por eles. Segundo, a recepção crítica do filme Cidade de Deus: cineastas, como Aurélio Michelis e Walter Salles, críticos literários, de cinema e jornalistas são unânimes ao afirmar que o filme trata sobre a "realidade brasileira”. Os processos de criação cinematográfica tendem a ficar ocultos sob a "realidade" mostrada no filme (ver cidadededeus.globo.com).

36 "A falta de homogeneidade étnica e racial faz dele [Brasil] um país multicultural por vocação, apesar das discriminaçōes "sutis" ocorrerem, e um país mais aberto às diversas identidades étnicas existentes no mundo. Ao mesmo tempo, sua vocação para a defesa do hibridismo ameniza as diferenças e cria um núcleo racial e cultural comum, como resultado da 
própria mistura. Também por isso o Brasil não é um país em que as formas violentamente excludentes do racismo biológico do passado ou do racismo cultural do presente sejam tão marcantes. É, na verdade, um país que rejeita teoricamente o racismo, embora na prática apresente sinais de discriminação dos negros e dos mestiços provenientes da mistura entre os vários negros e "brancos" que aqui aportaram e os indígenas que aqui já estavam. Entretanto, o mesmo não se pode dizer sobre as exclusões advindas da pobreza. Quando as discriminações raciais combinam-se com as discriminações contra o pobre, tem-se as mais claras situações de exclusão em diversos setores, por variados processos" (Zaluar, 1997, s. p.).

37 Para uma discussão mais detalhada sobre a teoria benjaminiana e suas possíveis aplicações ao romance de Paulo Lins, ver Fontana (2009).

38 De outra perspectiva, Mônica Fontana comparou o livro Abusado, de Caco Barcellos, a Cidade de Deus, de Paulo Lins. Seu trabalho tem inspirações muito próximas ao nosso, como o referencial benjaminiano para a análise da literatura, das narrativas orais e de suas reelaboraçōes escritas.

\section{BIBLIOGRAFIA}

ARANTES, Pedro Fiori. (2009), "Em busca do urbano: marxistas e a cidade de São Paulo nos anos de 1970". Novos Estudos Cebrap, 83: 103127.

BAKHTIN, Mikhail. (1997), Problemas da poética de Dostoiévski. Rio de Janeiro, Forense Universitária.

BECKER, Howard. (1996), "A Escola de Chicago". Mana, 2 (2): 177-188.

. (2009), Falando da sociedade: ensaio sobre as formas de representar o social. Rio de Janeiro, Jorge Zahar Editor.

BENJAMIN, Walter. (1986), "O narrador: considerações sobre a obra de Nikolai Leskov", in , Obras escolhidas: magia, técnica, arte e politica. São Paulo, Brasiliense.

BERMAN, Marshall. (2007), Tudo que é sólido desmancha no ar: a aventura da modernidade. São Paulo, Companhia das Letras.

BERNARDET, Jean-Claude. (2009), Cinema brasileiro: propostas para uma história. São Paulo, Companhia das Letras.
BENTES, Ivana. (2001), "Da estética à cosmética da fome". Jornal do Brasil, 8 set. . (2002), "Cidade de Deus promove turismo no inferno". O Estado de S. Paulo, 31 ago. . (2007), "Sertões e favelas no cinema brasileiro contemporâneo: estética e cosmética da fome". Alceu, 8 (15): 242-255.

BOURDIEU, Pierre. (1997), "Por una ciencia de las obras", in , Razones prácticas: sobre la teoría de la acción social, Barcelona, Anagrama. . (2003), "O campo científico", in Renato Ortiz (org.), A sociologia de Pierre Bourdieu, São Paulo, Olho d'Água.

. (2007), "Modos de produção e percepção artísticos", in Economia das trocas simbólicas, São Paulo, Perspectiva.

BOSI, Alfredo. (1994), História concisa da literatura brasileira. São Paulo, Cultrix.

BRESSON, Robert. (1979), Notas sobre el cinematógrafo. México, Era.

CAETANO, Maria do Rosário. (2007), Fernando Meirelles: biografia prematura. São Paulo, Imesp.

CARDOSO, Fernando Henrique. (2000), Negros em Florianópolis: relaçôes sociais e econômicas. Florianópolis, Insular.

CARDOSO, Ruth. (2011), Obra reunida. São Paulo, Mameluco.

CARDOSO DE OLIVEIRA, Roberto. (1988), “O que é isso que chamamos antropologia brasileira?", in Sobre o pensamento antropológico, Rio de Janeiro, Tempo Brasileiro.

CÉSAR, Amaranta. (2007), "Fabulação e figuração da alteridade em Cidade de Deus". Rua Revista de Arquitetura e Urbanismo, 2: 72-84.

CHALHOUB, Sidney. (1989), Visões da liberdade: uma história das últimas décadas de escravidão na corte. Campinas, tese de doutorado, Unicamp.

CLIFFORD, James. (1998), A experiência etnográfica: antropologia e literatura no século XX. Rio de Janeiro, Editora da UFRJ.

COMAROFF, Jean \& COMAROFF, John. (2010), "Etnografia e imaginação histórica". Proa, 2 (1): 1-55.

DAMATTA, Roberto. (1983), Carnavais, malandros e heróis: para uma sociologia do dilema brasileiro. Rio de Janeiro, Jorge Zahar Editor. 
DE LAURETIS, Teresa. (1984), Alice doesn't: feminism, semiotics and cinema. Bloomington, Indiana University Press.

DURHAM, Eunice. (2004), A dinâmica da cultura: ensaios de antropologia. São Paulo, Cosac Naify.

FONTANA, Mônica. (2009), Literatura e jornalismo: fato e ficção em abusado e Cidade de Deus. Recife, tese de doutorado em Letras, Universidade Federal de Pernambuco (UFPE).

GAY, Robert. (1994), Popular organization and democracy in Rio de Janeiro: a tale of two favelas. Philadelphia, Temple University Press.

GOLDSTEIN, Donna. (2003), Laughter out of place: race, class and sexuality in a Rio shantytown. Berkley, University of California Press.

GUYNN, William. (2006), Writing history in film. Nova York, Routledge.

HO, Wing-Chung. (2008), "Writing experience: does ethnography convey a crisis of representation or an ontological break with the everyday world?". Canadian Review of Sociology/Revue Canadienne de Sociologie, 45 (4): 343-365.

LEACH, Edmund. (1954), Political systems of Highland Burma: a study of Kachin social structure. Londres/Cambridge, London School of Economics and Political Science/Harvard University Press.

LEWIS, Oscar. (1970), Os filhos de Sanchez. Lisboa, Moraes Editores.

LINS DO REGO, José. (2011), Fogo Morto. Rio de Janeiro, José Olympio.

LINS, Paulo. ([1997] 2007), Cidade de Deus. São Paulo, Companhia das Letras.

MARCUS, George \& CUSHMAN, Dick. (1982), "Ethnographies as texts". Annual Review of Anthropology, 11: 25-69.

MASCARELLO, Fernando. (2004), "O dragão da cosmética da fome contra o grande público: uma análise do elitismo da cosmética da fome e suas relações com a Universidade". Intexto, 2 (11). Disponível em http://seer.ufrgs.br/intexto/article/view/4076/4449, consultado em 17 maio 2012 .

MELLO, Edir. (2010), Luz, câmera, ação: Cidade de Deus entre histórias e memórias. Rio de Janeiro, tese de doutorado, Universidade Estadual do Rio de Janeiro (UERJ).
PAIVA, Marco Aurélio Coelho de. (2010), O papagaio e o fonógrafo: os prosadores de ficção na Amazônia. Manaus, Fundação Universidade do Amazonas.

PARK, Robert. (1979), “A cidade: sugestôes para a investigação do comportamento humano no meio urbano", in Otávio Velho (org.), O fenômeno urbano, Rio de Janeiro, Jorge Zahar.

PEARLMAN, Janice. (2010), Favela: four decades of living on the edge in Rio de Janeiro. Oxford, Oxford University Press.

PERÉT, Flávia. (2009), Homossexualidade, violência e pobreza: as representaçôes do amor não hegemônico em Cidade de Deus e Estação Carandiru. Belo Horizonte, dissertação de mestrado, Universidade Federal de Minas Gerais (UFMG).

PINTO, Renan Freitas. (2008), A sociologia de Florestan Fernandes. Manaus, Editora da Universidade Federal do Amazonas.

PRADO, Keila Costa. (2008), “O que é meu é meu o que é seu é nosso: questôes de/sobre Cidade de Deus". Criação e Crítica, 1 (1): 31-43.

QUITÉRIO, Cesar. (2012), Cidade de Deus em perspectiva. São Paulo, dissertação de mestrado, Universidade Estadual de São Paulo.

RABINOW, Paul. (1977), Reflections on fieldwork in Morocco. Berkley, University of California Press

REDFIELD, Robert. (1940), "The folk society and culture". American Journal of Sociology, 45 (5): 731-742.

RIBEIRO, Paulo Jorge. (2000), "Cidade de Deus: memória e etnografia em Paulo Lins”. Lugar Comum - Estudos de Midia, Cultura e Democracia, 11: 73-98.

. (2003), "Cidade de Deus" na zona de contato: alguns impasses da crítica cultural contemporânea". Revista de Crítica Latinoamericana, 29 (57): 125-139.

. (2005), "Entre reflexividade e estetização da violência”. Trabalho apresentado no $29^{\circ}$ Encontro da Anpocs, Caxambu.

ROCHA, Glauber. (1963), Revisão crítica do cinema brasileiro. Rio de Janeiro, Civilização Brasileira.

ROCHA, Tatiana. (2007), Cidade de Deus: o arcaico e o moderno no romance contemporâneo. Brasília, dissertação de mestrado em teoria literária, Universidade de Brasília. 
SAID, Edward. (2003), O orientalismo: o Oriente como invenção do Ocidente. São Paulo, Companhia das Letras.

. (2005), Representaçôes do intelectual: as conferência Reith de 1993. São Paulo, Companhia das Letras.

(2011), Cultura e imperialismo. São Paulo, Companhia das Letras.

SEARLE, John R. (1975), "The logical status of fictional discourse". New Literary History, 6 (2): 319-332.

SCHWARZ, Roberto. (2001), "The City of God". New Left Review, 12: 102-112.

SONTAG, Susan. (2004), Sobre fotografia. São Paulo, Companhia das Letras.

VALLADARES, Lícia do Prado. (1978), Passa-se uma casa: análise do programa de remoção de favelas do Rio de Janeiro. Rio de Janeiro, Zahar Editores.

VISWESWARAN, Kamala. (1997), "Histories of feminist ethnography". Annual Review of Anthropology, 26: 591-621.

WELZER-LANG, Daniel. (2001), "A construção do masculino: dominação das mulheres e homofobia”. Revista de Estudos Feministas, 9 (2): 460-482.

WILDHAGEN, Joana Pinto. (2007), Fronteiras da falalbala. geografia do universo ficcional de $\mathrm{Ci}$ dade de Deus. Belo Horizonte, dissertação de mestrado em estudos literários, Universidade Federal de Minas Gerais (UFMG).

WIRTH, Louis. (1979), "O urbanismo como um modo de vida”, in Otávio Velho, O fenômeno urbano, Rio de Janeiro, Jorge Zahar.

XAVIER, Ismail. (2006), "Corrosão social, pragmatismo e ressentimento: vozes dissonantes no cinema brasileiro de resultados". Novos Estudos Cebrap, 75: 139-155.

ZALUAR, Alba. (1997), "Exclusão e políticas públicas: dilemas teóricos e alternativas políticas". Revista Brasileira de Ciências Sociais, 12 (35). Disponível em http:// www.scielo.br/scielo.php?pid=S0102$-69091997000300003 \&$ script=sci_arttext. . (2000), A máquina e a revolta: as organizaçōes populares e o significado da pobreza. São Paulo, Brasiliense.
(2005), "Entrevista concedida a Michel Misse, César Caldeira, Emilio Dellasoppa”. Revista Rio de Janeiro, 12: 5-35.

\section{Filmografia}

BRESSON, Robert (diretor). (1959), Pickpocket. França [título em português: $O$ batedor de carteiras].

- (1969), Une femme douce. França [título em português: Uma mulher delicada].

HITCHCOCK, Alfred (diretor). (1964), Marnie. Estados Unidos [título em português: Confissões de uma ladra].

MEIRELLES, Fernando \& Lund, Katia (diretores). (2002), Cidade de Deus. Brasil.

ROCHA, Glauber (diretor). (1961), Barravento. Brasil.

(1964), Deus e o diabo na terra do sol. Brasil.

(1972), Câncer. Brasil.

SALLES JR., Walter (diretor). (1998), Central do Brasil. Brasil.

SALLES, João Moreira \& LUND, Kátia (diretores). (1999), Notícias de uma guerra particular. Brasil.

SANTOS, Nelson Pereira dos (diretor). (1955), Rio 40 graus. Brasil.

. (1957), Rio zona norte.

(1963), Vidas secas. Brasil.

VIDIGAL, Luciano \& Borges, Cadu (diretores). (2012), Cidade de Deus: dez anos depois. Brasil. WADDINGTON, Andrucha (diretor). (2000), $E u$, tu, eles. Brasil.

Fontes da internet

"ANTÔNIO Abujamra entrevista Paulo Lins". Vídeo em três partes. Disponível em http:// www.youtube.com/watch?v=114kZWMbCaw.

"CIDADE de Deus: (o filme)". Disponível em cidadededeus.globo.com.

"ENTREVISTA de Eunice Ribeiro Durham por Lilian de Lucca Torres". Disponível em http:// www.pontourbe.net/04/entrevista4eunice.html.

"FERNANDO Meirelles no Roda Viva da TV Cultura”. Vídeo em nove partes. Disponível em http:// www.youtube.com/watch?v=nsh_HZBO_ic. 
"HELOÍSA Buarque de Hollanda entrevista Paulo Lins". Disponível em http://www.heloisabuarquedehollanda.com.br/? $\mathrm{p}=712$.

"HIPERMASCULINIDADE" leva jovem ao mundo do crime: entrevista de Alba Zaluar à Folha de S. Paulo em 12/7/2004". Disponível em www.ims.uerj.br/nupevi/artigos_midia/ Hiperm.pdf.

"MVBILL e a polêmica com "Cidade de Deus". Clique Music UOL, 22/1/2003. Disponível em http://cliquemusic.uol.com.br/materias/ ver/mv-bill-e-a-polemica-com--i-cidade-de-deus--i-.

"NARRADORES Urbanos: Ruth Cardoso". Video de Ana Luiza Carvalho da Rocha e Cornelia Eckert. Vibrant - Virtual Brazilian Anthropology. Disponível em http://www.vibrant.org.br/ issues/v8n2/ana-luiza-carvalho-da-rocha-cornelia-eckert-urban-narrators-ruth-cardoso/.

PORTAL Comunitário da Cidade de Deus. Site: www.cidadededeus.org.br.

"INTERFERÊNCIA: Ferréz entrevista Paulo Lins". Disponível em http://interferencia.art. br/2009/08/027-paulo-lins-2/.

"LIÇÕES que a Cepal deixou ao Brasil", de Luiz Sugimoto. Disponível em http://www.unicamp.br/unicamp/unicamp_hoje/ju/dezembro2006/ju347pag09.html. 


\section{A INTERTEXTUALIDADE E SUA TEIA: DA ETNOGRAFIA AO ROMANCE E DO ROMANCE AO FILME}

\section{José Hildo de Oliveira Filho}

Palavras-chave: Cidade de Deus; Antropologia urbana; Etnografia; Cinema; Intertextualidade.

Neste trabalho, analisamos a etnografia de Alba Zaluar $A$ máquina e a revolta, contrapondo-a com os discursos ficcionais do romance Cidade de Deus, de Paulo Lins, e do filme homônimo, de Fernando Meirelles. Buscamos salientar os dilemas éticos da antropologia e das diversas formas de expressão estéticas, além dos problemas específicos levantados pelas diversas formas de representação dos moradores de Cidade de Deus presentes na investigação antropológica, no romance e no filme. Analisamos tanto os contextos históricos que condicionaram o desenvolvimento dessas obras como a sua singularidade. Ressaltamos ainda o fato de que esses discursos sobre Cidade de Deus confrontaram-se publicamente, revelando suas posições políticas e éticas sobre pobreza e violência.

\section{THE INTERTEXTUALITY AND ITS WEB, FROM ETHNOGRAPHY TO NOVEL AND FROM NOVEL TO FILM}

José Hildo de Oliveira Filho

Keywords: Cidade de Deus; Urban anthropology; Ethics in Ethnography; Contemporary Brazilian cinema; Intertextuality.

The article analyzes Alba Zaluar's ethnography A Máquina e a Revolta [the Machine and the Revolt], confronting it with the fictional discourses of Paulo Lins' novel Cidade de Deus and the homonymous movie directed by Fernando Meirelles. In so doing, it seeks to discuss the ethical dilemmas of an anthropological investigation when confronted with the discourses exposed by the novel and the film, discussing as well some specific problems raised by the different forms of representation of the Cidade de Deus dwellers, as appeared in the anthropological research, in the novel, and the film. The historical context of each of the discourses is also analyzed in order to show their particularities. Attention is also given to the public debate confronting these different discourses on the press, what gave opportunity to reveal their different political and ethical positions about poverty and urban violence.

\section{L'INTERTEXTUALITÉ ET SA TRAME. DE L'ETHNOGRAPHIE AU ROMAN ET DU ROMAN AU FILM}

José Hildo de Oliveira Filho

Mots-clés: Cidade de Deus; Anthropologie urbaine; Cinéma; Intertextualité.

Ce travail analyse l'étude ethnographique d'Alba Zaluar, $A$ máquina e a revolta, en l'opposant aux discours fictionnels du roman Cidade de Deus de Paulo Lins et du film homonyme de Fernando Meirelles. L'objectif est de souligner les dilemmes éthiques de l'anthropologie et des différentes formes d'expression artistiques, ainsi que les problèmes spécifiques soulevés par les formes de représentation des habitants de Cidade de Deus présentes dans l'investigation anthropologique, dans le roman et dans le film. L'analyse porte autant sur les contextes historiques qui ont conditionné le développement de ces oeuvres que sur leur singularité. En outre, les confrontations publiques entre ces différents discours sur le bidonville Cidade de Deus révèlent leurs positions politiques et éthiques sur la pauvreté et la violence. 